\title{
PROGRESS IN DEALING WITH MEASUREMENT AND QUALITY PROBLEMS IN PLANNING LAND AND WATER USE
}

\author{
AYers Brinser \\ New England Board of Higher Education and University of Michigan
}

$7 H E$ WORD "progress" in the title assigned to this essay implies that
over some assumed period of time we have enhanced our ability to use. If the validity of the evidence on this point were to be attested by sheer bulk, then the burgeoning bibliography on measurement for resource planning-particularly in the area of water resources-establishes an overwhelming case for progress. On the other hand, if this spate of writing were viewed from a less sanguine point of view, then it would seem that the proliferation of books and articles was in itself evidence that economists and other social scientists are actually revealing their basic uncertainty about how to proceed with assessing possible alternatives in resource planning. This is not to deny that a growing awareness of unresolved complexity is a kind of fruitful development, but it can be called progress only in this special sense. The discussion that follows rests on this latter point of view. ${ }^{1}$

To select an arbitrary point of departure-the end of World War IIthere has been since that time a significant development in the use of mathematical techniques both to identify the relevant objectives and to test the means of achieving those objectives of land and water resource planning. If "progress" embodies any meaning of importance, it would be that the effort to give greater precision to the measurement of the net returns from investment in land and water resource development has been a major factor in generating a still greater effort to define what the proper means of directing such planning are. ${ }^{2}$ This, in turn, has served not to identify the ends, but rather to extend the understanding of the range of their significance. Thus, an attempt to assess this change must be something more than a mere enumeration of the milestones on a road that is assumed to lead to a more certain future. Instead, the

\footnotetext{
${ }^{1}$ It is also assumed here that the intention assigned to this discussion was not to provide a compendium omnium of the field, useful though that may be. For this reason, no attempt has been made to present a complete bibliography of the field.

${ }^{2}$ See, for example, Hollis B. Chenery, "Interindustry Research and Economic Development," American Economic Review, L, No. 2: 649-652 (May 1960), where he makes the statement, "The main results to date of the use of input-output analysis and mathematical programming in the study of economic development have been the clarification of concepts and an estimation of their quantitative significance." (p. 652).
} 
focus of inquiry must be the interacting components of the process of development.

This process may be examined from four points of view-points of view that are not independent points of departure in four directions, but rather four positions from which to observe the interrelationships of the set from different perspectives. First, there are the external factors that influence these changes and the ways in which their impact is made manifest. Second, it is necessary to recognize the increasing sophistication of quantitative measurement techniques. Third, and of growing importance, is the dawning awareness of the significance of quality and values as they are related to both the ends and means of resource planning. ${ }^{3}$ Finally, is the issue of how the qualitative and quantitative elements of the processes interact-in short, the central conceptual problem. ${ }^{4}$

\section{II}

The most apparent external factor influencing choice in planning land and water resource development is the increasing commitment of government-state, federal and local-in the field of resource development. Not only has this opened to public debate the general issue of the efficiency of such expenditures, it has also revealed to public scrutiny the various processes by which quantitative measurements are made; or evaded, and the hypotheses of relevance from which the measurements stem. The necessity to assess the quality of goods and services flowing from such public investment, as well as the quantity, is now inescapable.

Movement in the direction of greater governmental participation has been accelerated by four developments. The first of these is the increasing acceptance by public agencies of the obligation to mesh public re-

\footnotetext{
"This cannot be claimed to be a new insight on the part of present day economists. It is rather a condition about which they are becoming increasingly articulate and aware as an issue of economic significance. J. K. Galbraith's The Affuent Society substantiates the first point. On the second, John Brewster has wrtiten, "But neither pay nor the kinds of goods and services has any scientific standing as a means of designating the economic and noneconomic nature of employments. For the foundation axiom of economic theory is that men seek to act in ways that will maximize their satisfactions. In line with this presupposition, the term 'economic' means simply the 'rational' accomplishment of given purposes with the least possible expenditure of limited means: time, energy, personal capacities, and other resources. Thus any activity is economic to the extent that it is accomplished in this way, irrespective of whether it be done with or without pay, and also irrespective of the kind of goods or services it yields-whether a poem, a prayer, a painting, a pair of shoes or an ear of corn." John M. Brewster, "Beliefs, Values and Economic Development," J. Farm Econ., XLIII, No. 4, part 1: p. 781 (November 1961).

${ }^{4}$ See, for example, S. V. Ciriacy-Wantrup, "Benefit-Cost Analysis and Public Resource Development," J. Farm Econ., XXXVII, No. 4: 676-689 (November 1955); and also his Conceptual Problems in Projecting the Demand for Land and Water, Giannini Foundation, Paper No. 176, University of California, Berkeley, May 1959. See also Stuart Hampshire, Thought and Action (London: Chatto and Windus, 1959).
} 
source investment with private investment as a necessary program for continuing economic development. A second aspect of this expanded public interest is the increase in the use of government funds in resource development to enhance the quality of living. A clear example of this broader spectrum of interest is the increasing concern with expanding the facilities for outdoor recreation. An especially important feature of this public commitment to natural resource development is the greater readiness of government to assume responsibility for investment in areas where private investment fails to develop full-scale social and economic benefits either in the present or over time. As the more favorable resource sites are exploited, it is falling more and more to government to invest in these less obvious opportunities. ${ }^{5}$ Finally, in addition to the trend toward the use of broader criteria to justify public investment in resource development is the parallel growth of public regulation of the use of land and water resources as, for example, in the case of water and air pollution control. ${ }^{\circ}$

What once appeared to be the straightforward problem of examining the ratio of direct monetary benefits to direct costs has become the vastly more complex one of evaluating secondary or off-site benefits, spillover and income distribution effects, consequences of investment inputs for economic growth, adjudication between social and private time preferences and rates of discount, opportunity cost calculations, the indivisibility of costs and benefits, and host of other issues which of necessity are being subjected to increasingly rigorous inquiry. It would require a singular lack of concern for an exposed flank to assert that the recognition of the existence of these issues has been attended by their solution. But if "progress" is taken to mean an increasing clarification of the relevant questions, then there has been improvement. To support this contention, the evolution of criteria in the so-called Green Book ${ }^{7}$ may be cited. The fate of the latest attempt to improve that criteria should be sufficient caution not to claim too much for progress, but the cutting edge of the argument can be conceded to be in the direction of economic rectitude.

\footnotetext{
${ }^{B}$ The process of thrusting upon government the less desirable investment opportunities was once described by John M. Gaus as "ash can socialism," a term intended to decry the obligation rather than the means of meeting it.

"The significance of this point is brought out by Edward S. Mason in "The Role of Government in Economic Development." American Economic Review, L, No. 2: 636-641 (May 1960). In describing this issue, Mason indicates a distinction that must be taken into account in setting up models for measuring the consequences of government investment. "It may be fruitful to distinguish the role of government in the assisting of expansion of the supply of resources from its influence on the direction of resource use and its participation in resource management." (p. 639).

"Subcommittee on Benefits and Costs, Proposed Practices for Economic Analysis of River Basin Projects, Inter-Agency Basin Committee, 1958, to give it its full title.
} 
One aspect of this greater government commitment to resource development that has specific bearing on the problem of measurement is the growing concern with water resources and land as space relative to that with agricultural land. This shift is owing in part to the accelerating urbanization of the United States. The obvious consequence of this is that the clientele support for water resource investment, recreation, urban land development, and kindred projects is becoming more articulate and is exerting greater leverage on Congressional appropriations. At the same time, the relative importance of agricultural land as the basic factor in food and fiber production has diminished.

The present agricultural land program grew out of the conservation and income crises of the 1930's. That program is still suffering from the fact that it attempted to wed incompatible objectives-conservation, which was aimed at avoiding a famine of land resources, and raising farm income, which was in the doldrums because of a redundant supply from those same land resources. The success of the conservation program is buried under the mound of farm surpluses that has been produced by the farm income support measures. Regardless of the rationale of the argument, it would be hard today to secure major government support for an agricultural land resource development program.

On the other hand, water resources and land as space are presented as conservation problems-as vital resource pools threatened by ultimate shortages of supply. ${ }^{8}$ This is the kind of issue that elicits Congressional support. Income redistribution, the core of the farm problem, is in contrast a far less agreeable question to tackle, if for no other reason than that any solution cuts close to the tender quick of political ideology. This is not an attempt to forecast what will happen when the full implications of the income effects of public investment in water resources and land as space become too obvious to be evaded.

Regardless of what obligations may be accepted in the future, government stands vis-a-vis agricultural land in a posture quite different from that with which it faces water and land as space. The responsibility for developing and managing agricultural land falls primarly upon the private sector of the economy, farmers and ranchers. On the other hand, in the case of water and land as space the public interest is the dominant concern. They are central to the government commitment for economic development. The investment opportunities they present are uniquely

\footnotetext{
${ }^{8}$ One example of the growing concern with water scarcity is the Report of the Select Committee on National Water Resources (Washington Government Printing Office, 1961). This instance may be multiplied by an increasing number of attacks and plans of attack on water problems by various departments of government, both by those traditionally concerned with water, such as the Corps of Army Engineers, the Soil Conservation Service and the Bureau of Reclamation, and by the new agencies such as the Department of Health, Education and Welfare.
} 
in the public sphere, not only because of the nature of the "market" for their services, the nonmarketable character of goods and services they should provide, but also because of the intention of public investment which embraces objectives beyond the scope at the market calculus. ${ }^{9}$

In part because investment in water resources initially involved large public expenditure under conditions in which direct costs and benefits fall under public control, the original problem of measurement was more straight forward than when the objectives of resource planning had to be approached largely through the influences on private investors, as was the case with many agricultural land-planning programs. But the management and development of water and land as space resources also creates more direct involvement with such problems as the indivisibility of costs and benefits and the complex issues of time preferences and rates of discount. Thus, there is the unavoidable necessity to extend and intensify the efforts to measure more accurately both the quantity and quality of the net yield from investment in water development. As long as the structure of the organization of water resource agencies continues to reflect the competition for control of water programs, measurement criteria may be expected to remain fluid and the objective of a continuing search for greater precision. The agencies involved are under pressure to develop their sensitivity to the realities that face their various clienteles, a benefit that may be worth the cost in administrative duplication and friction. The fact that water resources and land as space embrace such a wide array of the public interests offers hope that these differences may be more readily reconciled in a general policy of economic development than has been true of agricultural land policy. For one reason, the need is more clear and specific. Should this prediction be realized, a broadly conceived system of measurement for choosing among alternative plans would be a significant instrument for such reconciliation. ${ }^{10}$

\footnotetext{
" "Of course, when an economist analyzes individual market behavior, he may find the want satisfaction criterion extremely useful; but, when he analyzes public policy, he often finds himself concerned, as any reading of economics will show, more with the impact of policy on opportunities for the individual than with its impact on resultant states of mind. This is understandable on the hypothesis that he assumes a division of labor between government and the individual, in which the former tries to shape opportunities and the latter to exploit them. Not only-to elaborate the hypothesis-does public policy often not aim directly at want satisfaction, it aims instead at creating conditions in which appropriate want satisfying activity will be called forth from the individual." Charles E. Lindblom, "The Handling of Norms and Policy Analysis," The Allocation of Economic Resources-Essays in Honor of Bernard Francis Haley (Stanford: Stanford University Press, 1959) 168-169.

${ }^{10}$ Compare Vincent Ostrom, "The Political Economy of Water Development," American Economic Review, LII, No. 2: 450-458 (May 1962). Ostrom emphasizes the point that, "The structure of organizational arrangement implicitly determines the basis for distinguishing the sets of events to be controlled, the order of preferences for ranking the values to be achieved by organized activities, and the standards
} 
With the multiplication of water resource programs and agencies has come the usual cry that is the leitmotiv of resource policy, we must integrate the activities of the various agencies responsible for these designs and their operation. In part, this demand for integration and coordination arises from the contrast with the physical unity of river basin systems. Whether this physical unity can or should be imposed by analogy on the social, political and economic problems of river basins is a critical issue, bringing into sharp relief the need for precise definition of the problem to be solved and the ends and means to be incorporated in the planning models. Equally important and becoming equally obvious is the fact that such models must embrace a wide range of nonmarket economic values and socio-political forces with which economic efficiency must be reconciled. ${ }^{11}$

Regardless of the success in bringing these data within the scope of present models of economic measurement, the assembling of the facts of hydrology, topography, climate, and similar physical phenomena have provided a hard core from which to expand the search for techniques of measurement that yield a common standard for assessing the relationship of physical changes to economic choice and social costs and benefits. This would seem to be the area of greatest progress in developing systems of measurement for resource planning. In part because of the close association with engineering data, major emphasis has been placed on applying mathematical techniques to coerce economic data into a relevant relationship with the working knowledge of the engineers. One of the most recent and rigorously executed projects of this sort has been the study at Harvard University which produced The Design of Water Resource Systems. ${ }^{12}$ This is but one of a series of extensive investigations of the possible application of quantitative measurement techniques to the economics of investment in water resources, which now constitute the familiar canon for all workers in this field.

\section{III}

If the only test of the value of that research were its influence in providing answers for the planning of water and land resource investment,

for determining the relevancy of information to be communicated in the decision making process. Since the patterns of organization have a fundamental influence upon the development of perspectives, values, and ideas regarding resource policies and patterns of resource development, any question of comprehensive planning must necessarily involve questions about the design of organizational arrangements." (p. 456).

1" On this point, see Henry C. Hart, The Dark Missouri (Madison: The University of Wisconsin Press, 1957).

${ }^{12}$ Arthur Maass, Maynard and Huffschmidt, Robert Dorfman, Harold A. Thomas, Jr., Stephen A. Marglen, and Gordon Fair, The Design of Water Resource Systems (Cambridge: Harvard University Press, 1962). 
the inescapable conclusion would be that within the past decade there has been little progress in measurement. If, on the other hand, an additional test is applied-namely, the value of this research in defining the relevant questions for planners to answer and in discriminating among alternative means to given ends-then over the past decade progress has been considerable. Two specific things emerge from these studies. The first is a clarification of the more fruitful lines for empirical research. The second is, somewhat paradoxically, a revelation of the ultimate importance of quality and values in planning design and decisions. It would seem that the greater the refinement of quantitative measurement, the more clear the central importance of qualitative factors as criteria for planning become.

Tolley and Harrell, for example, pose the question, "Do accepted methods of estimating benefits and costs provide a conceptually accurate procedure for measuring the change in national output that would result from a project? Moreover, even if the change in national output is measured correctly, how well does this take account of the effects of the project upon people's satisfactions? The answers to these questions are usually among the assumptions of evaluation procedures." ${ }^{13}$ Their reply is that,

In spite of shortcomings of estimates, the recommendation here is not that benefit-cost analysis be discarded. Benefit-cost analysis appears desirable as a brake on complete disregard of national output considerations. But the recommendation is made to supplement the usual estimates of direct costs and benefits with as accurate tracing as possible of chains of specific project effects. This should help improve estimates of direct benefits and costs, throw light on secondary benefits, and bring out project effects on goals other than national output. ${ }^{14}$

The growing awareness of the importance of nonmarket values has brought into the open in the field of resource planning the close interrelationship between the assumed ends of economic activity on which quantitative measurement is based and the emerging value systems that are, in effect, shaped by the starting hypotheses of what is desirable and by the means for achieving assigned goals. ${ }^{15}$

${ }^{13}$ George S. Tolley and Cleon Harrell, "Extensions of Benefit-Cost Analysis," American Economic Review, LII, No. 2: p. 460 (May 1962).

${ }^{14} \mathrm{Ibid}$., p. 463. A very useful discussion of the limitations of the use of national income and product data to measure net social returns can be found in Moses Abramowitz's article, "The Welfare Interpretation of Secular Trends in National Income and Product," in The Allocation of Economic Resources-Essays in Honor of Bernard Francis Haley (Stanford: Stanford University Press, 1959) pp. 1-22.

${ }^{15}$ "Scientific terms become value loaded because society is made up of human beings following purposes. A 'disinterested social science' is from this point of view, pure nonsense. It never existed, and never will exist. We can make our thinking strictly rational in spite of this, but only by facing the valuations, not by evading 
Gunnar Myrdal faced up to this problem some twenty years ago in his An American Dilemma. ${ }^{16}$ His subsequent work in the field of economic development has enabled him to elaborate his original position on these issues. Perhaps the most significant of his statements can be found in Economic Theory and Underdeveloped Regions ${ }^{17}$ and An International Economy-Problems and Prospects. ${ }^{18}$ What Myrdal had to say about the contingency of values, the interrelationship between ends and means, the Procrustean nature of conventional economic analysis in predetermining the results of measurement by the implicit assumptions in the tools of measurement all have considerable relevance for resource planning, both in the United States and in the underdeveloped areas.

With land and water resource planning, especially the former, taking on greater significance in the public sphere, the problem of assessing the quality of returns from investment can no longer be relegated to the status of a side issue. That this is at last an accepted point of view may be demonstrated by the fact that "secondary benefits" is no longer considered to be adequate to describe the vast ranges of effects induced by resource investment. Indeed, and distinction among the qualities of benefits no longer has a very useful meaning. Planning to implement public policy certainly must aim at economic efficiency, but as a means and not an end. And as the real distinction between ends and means becomes more ambivalent, the need to establish some comparative measurements of quality and value grows. The recognition that this is not only a real issue but that it is one that can be made to yield to rigorous inquiry is a major aspect of the progress that has been made in the area of measurement for planning purposes within the past decade.

This issue comes into sharpest focus in the investigations now. being made into the decision-making process. Since planning decisions are primarily concerned with the future, an essential aspect of the decisionmaking problem is forecasting or prediction. As Theil puts his problem,

them." Gunnar Myrdal, Value in Social Theory, Paul Streeten, ed., (New York: Harper and Bros., 1958) p. 164. Historically, economics has dealt with norms and values by attempting to neutralize them. They make their appearance in analysis usually by implication. To face them directly, frequently induces the kind of trauma usually ascribed to fearsome creatures. For a discussion of this point, see A. C. Graham, The Problem of Value (London: Hutchinson University Library, 1961), in which he makes the point, "Each discovery of the subjectivity of what seemed objective induces a temporary vertigo, but we soon recover our bearings." (p. 16).

${ }^{10}$ Gunnar Myrdal, An American Dilemma-The Negro Problem and Modern Democracy (New York: Harper \& Bros., 1944).

${ }^{17}$ Gunnar Myrdal, Economic Theory and Underdeveloped Regions (London: Dukworth, 1957).

${ }^{18}$ Gunnar Myrdal, An International Economy-Problems and Prospects (London: Rutledge and Kegan Paul, 1956). 
"Rational policy making is the adaptation of the policy maker's instruments to his changing environment in such a way that the result is 'good' or 'optimal.' . . . First, the changing environment has to be predicted; second, a forecast of the effects of the policy maker's measures, that is, of changes of instrument values, is required; third, a plan of action must be made." ${ }^{18}$ He adds, “. . . much will be gained if policy makers act in a more conscious manner by realizing explicity what are their goals, what are the things over which they have direct command, what are their unknowns, and especially, what are the interrelationships among all these variables."20 The essential point is that the unknowns, the uncertainties, and the evolving pattern of values must be recognized for what they are-not disturbances to be eliminated from measurement of predicted consequences, but rather essential elements of both cause and effect to be incorporated in a measurement process. They are a critical part of both the means of making decision and the quality of the result.

Studies in decision making come face to face with the basic conceptual problem of measurement-the translation of data from the physical world into a scheme of human values. Given the fact that interacting change is characteristic of the world in which decisions are made, the relevant point of investigation is the process of adaptation to change and efforts to maintain some kind of control of change. Simon makes the point that the world in which the economic planner attempts to make predictions and control the flow of events is one of great complexity of phenomena in highly unstable relationships. This is not the world that supports the hypothesis from which the classical equilibrium model is derived. As we become more aware of the real nature of the environment, the ability of that model to yield useful insights for policy, "must be considered anew." The conventional economic man is a creature of the equilibrium model. If the real environment is a dynamic disequilibrium characterized by the complexity of phenomena and the instability of forces, then "to explain ... . [man's] behavior in the face of this complexity, the theory must describe him as something more than a featureless, adaptive organism; it must incorporate at least some description of the processes and mechanisms through which the adaptation takes place."21 He goes on to make the further point that, "Most real life choices still lie beyond

${ }^{19} \mathrm{H}$. Theil, Economic Forecasts and Policy, 2nd rev. ed. (Amsterdam: NorthHolland Publishing Company, 1961) p. 3.

${ }^{20}$ Ibid., p. 557. Jan Tinbergen develops this point quite rigorously and fully in his On the Theory of Economic Policy (Amsterdam: North-Holland Publishing Company, 1952). For a useful summary of literature dealing with these issues, see Carl A. Fox, "The Study of Interactions Between Agriculture and the Non-farm Economy: Local, Regional and National," J. Farm Econ. XVLI, No. 1: 1-34 (February 1962).

${ }^{23}$ Herbert A. Simon, "Theories of Decision Making in Economics and Behavioral Science," American Economic Review, XLIX, No. 3; 255-256 (June 1959). 
the reach of maximizing techniques-unless the situations are heroically simplified by drastic approximations." 22

The investigation of decision making as a central aspect of planning has had two very fruitful results. It has brought together the use of machine techniques and the wide range of nonmarket values as they are expressed in human reactions and human creativity. Furthermore, it provides a model in which quantity and quality can be observed in their relevant relations to one another. In addition, this model clearly reveals planning as a process in which time, uncertainty and the emerging articulation of normative values can be observed as interacting variables shaping the direction of a changing continuum. Thus, it extends the measurement of planning alternatives beyond the narrow limits imposed by an arbitrary unit of calculation. In other words, it offers a release from the concept of economic man and sets up the more realistic frame of reference of man in society living over time. These are the central factors to be assessed in resource planning. ${ }^{23}$

In such models, man ceases to be merely a datum, frequently ignored because his responses could not be measured by the techniques at hand, and assumes the creative role as an integral part of the process of development. It provides an opportunity to approach what is establishing itself as the relevant issue in resource planning as defined by Chandler Morse and Harold Barnett, in their paper on Natural Resources and Economic Growth.

In short, the resource problem is one of continual accommodation, adjustment, to an ever-changing economic resource quality spectrum. The physical properties of the natural resource base impose a series of initial constraints on the growth and progress of mankind, but the resource spectrum undergoes a kaleidoscopic change through time, with every turn of the crank of history providing a new pattern. Substitutability-the result of man's technological ingenuity and organizational wisdom-offers those who are nimble a multitude of opportunities for escape. The fact of constraint does not disappear, it merely changes character. New constraints replace the old. The burden of ... this paper is that resources impose a far less rigid and certain obstacle to a continued increase in the return to effort than economists have been wont to believe. It follows, if this be so, that solution of the quantitative problem can be entrusted (mainly) to natural scientists and engineers, while economists and other social scientists shift

\footnotetext{
${ }^{32}$ Ibid., p. 259. See also Robert Dorfman, "Operations Research," American Economic Review, L: 575-623 (September 1960).

For further discussion of the use of machine techniques to estimate the nature and possible effects that humans may have on the future system performance, see especially Robert M. Rauner and Wilber A. Steger, "Simulation and Long-Range Planning for Resource Allocation," The Quarterly Journal of Economics, LXXVI, No. 2: 219-245 (May 1962). See also G. H. Orcutt, M. Greenberger, J. Korbel, and A. M. Rivlin, Microanalysis of Socioeconomic Systems-A Simulation Study (New York: Harper \& Bros., 1961).
} 
their attention to the institutional aspects and the qualitative dimensions of growth. From this standpoint it seems probable that man will eventually wish, for purely qualitative reasons, to set the limits to the growth of both population and product that are well within the bounds of what is quantitatively possible. That is to say, Man-not Nature-will impose the ultimate constraint. To devise criteria and mechanisms for effecting this limitation will be an important task. ${ }^{24}$

This statement of the context of resource planning is, on the one hand, an outgrowth of the effort to provide a precise measurement of consequences flowing from such plan. On the other hand, it is an example of the progress that can be attributed to the efforts to make measurement a more useful tool for planning. In that sense, the real progress that has been made is a redefinition of the actual question to be asked. This is not a new question, but rather an acceptance of the fact that because it has taken its place as the central question it is important to mount an analytical attack that will lead to useful answers. This new line of inquiry will require both rigorous research in the quantitative area and the use of quantitative measurement techniques, not as ever more sophisticated exercises in economic elegance, but as instruments of creative conceptualization. As yet, such a complete synthesis of techniques, data and insight is to be achieved.

One of the more interesting new lines of inquiry being opened in this area is the work of G.L.S. Shackle, particularly in his latest book, $D e-$ cision, Order, and Time in Human Affairs. Shackle's conceptual apparatus rests on a definition of decision as a creative act. If this is accepted, then logically it is impossible to postulate either the classical equilibrium system, or the opposite, a world of chaos which some psychological theories have suggested. ${ }^{25}$ Thus, man as the agent is at the heart of the system with the full recognition that creativity is an aspect of his unpredictability. "The set of rival hypothetical outcomes of each available action is not prescribed like those of a game with completely stated

${ }^{24}$ Chandler Morse and Harold J. Barnett, "A Theoretical Analysis of Resource Scarcity in Economic Growth Under Strict Parametric Constraints" Natural Resources and Economic Growth, Joseph J. Spengler, ed., (Washington: Resources for the Future, Inc., 1961) pp. 46-47.

${ }_{2 s}$ "In a predestined world, decision would be illusory; in a world of perfect foreknowledge, empty; in a world without natural order, powerless. Our intuitive attitude to life implies non-illusory, non-empty, non-powerless decision. This attitude is revealed by our ordinary speech, in which the word decision suggests the power to initiate a new train of impulses in the wave-pattern of history. Since decision in this sense excludes both perfect foresight and anarchy in nature, it must be defined as choice in face of bounded uncertainty. If decisions are creative, each injecting into history something essentially novel, something which is not purely the inevitable outgrowth of the past, decisions are unpredictable and so, therefore, is history." G. L. S. Shackle, Decision, Order, and Time in Human Affairs (Cambridge: Cambridge University Press, 1961) p. 43. 
rules. The outcomes imagined by the decision-maker for each act may not be determined by his past but may contain something not to be found in any account of his experience; an element of 'inspiration." "26 By setting up the frame of reference in these terms, Shackle establishes a useful point of departure for testing the relevance of data and for following the processes of interaction in a system of contingencies. It is not a matter of substituting human intuition for data, but rather of making man, his capacity to reason, and human imagination a part of the data. ${ }^{27}$ Here, conceptualization provides a verbal framework by which the numbers can be given meaning.

${ }^{3}$ Loc. cit.

${ }^{27}$ "To play its part in decision, imagination must be constrained to be congruous with what the decision-maker knows of the nature of things in general and of human nature: and constrained also to be congruous with the time available for transformation of the actual situation at the decision-maker's present into his desired situation at its specific calendar location." Ibid., p. 11. See also James W. Angell, "Uncertainty, Likelihoods, and Investment in Decisions," The Quarterly Journal of Economics, LXXIV, No. 1: 1-28 (February 1960), and Nelson Goodman, Fact, Fiction and Forecast (Cambridge: Harvard University Press, 1955), particularly chapter IV. 